\title{
Patterns in Horse-Human Relationships: The Case of Wales
}

\author{
Helen Sampson
}

School of Social Sciences, Cardiff University, United Kingdom sampsonh@cf.ac.uk

\begin{abstract}
This paper explores some of the different relationships that horses and humans experience in the case study country of Wales. In doing so, it pays attention to differential patterns of equine care/lack of care and explores these from a sociological perspective considering evidence of the potential impact of cultural practices and socio-economic status in particular. The paper concludes that access to common lands and "fly grazing" may be associated with specific values and norms which may result in equine neglect, while indicators of socio-economic deprivation and patterns of equine neglect do not seem to be related. The paper highlights the variation in equine care across this relatively small national population and suggests some areas where further explanatory work could usefully be undertaken in order for us to better understand the carerelationships between horses and their keepers.
\end{abstract}

\section{Keywords}

horses - neglect - commons - travellers - socio-economic deprivation - welfare

In 1954, one of the founders of the "Horse of the Year Show" (a major equestrian event held annually in the UK to mark and celebrate the end of the equestrian season) commissioned a poem to be read out at the end of each show. This ode to "The Horse" (Duncan, 1964) is a moving piece that speaks of the horse's nobility, strength, beauty, and patience. It is written with admiration and emotion, and it broadcasts human appreciation for horses, as nonhuman animals, in all walks of life. Yet the words seem empty, and a far from honest account of human/horse relations, as I stand and look over the stable door of

(C) HELEN SAMPSON, 2018 | DOI:10.1163/15685306-12341506

This is an open access article distributed under the terms of the prevailing CC-BY-NC license at the time of publication. 
the latest mare to be rescued by my local horse sanctuary. At around twenty years old, she is believed to be "in foal." Found abandoned and uncared for on Gelligaer common in South Wales, "Doris," as the sanctuary named her, is all skin and bone with huge, soft brown eyes testifying to a gentle soul. Viewing her, as I recall the words of the Hoys poem, I wonder how it is that humans, as a species, show such lack of responsibility and callous disregard for horses on the one hand, while lavishing them with luxury and celebrating them with poetry, art, and even music, on the other. This question broadly describes the central focus and concern for this paper.

The paper begins with an outline of the problem of the abuse of horses by humans in Wales and the form this takes. Following a brief account of the data collection methods underpinning the paper, it explores data relating to the commonly hypothesized explanations of equine abuse in the devolved United Kingdom (UK) nation of Wales. Then, by contrast, it considers the work of a well-known society working to protect and rescue horses in the old industrial region of South Wales: The Society for the Welfare of Horses and Ponies (sWHP). In discussing the findings, it moves away from more traditional psychopathological explanations of nonhuman animal abuse to consider more sociological themes, and in concluding, it offers suggestions for the ways in which equine-human relationships can be further explored making use of a socialscience perspective in order to better understand the complex and multistranded relationships between humans and horses in contemporary society.

\section{Outlining the Problem of Harm to Equines within Wales}

Wales is one of four countries constituting the United Kingdom (UK). Following the Government of Wales Act 1998, a degree of governmental responsibility has been devolved to Wales from the UK central government at Westminster. In line with such responsibilities, the Welsh government has enacted legislation in conjunction with the identification of equines (via so-called passports) and the control of illegal grazing, also termed "fly grazing," both of which are relevant to this paper. Wales constitutes around $10 \%$ of the land area of the U K and is estimated to have between nine and eleven percent of the approximately 842,653 to 1,350 ,ooo horses who are owned in the UK (Boden, Parkin, Yates, Mellor, \& Kao, 2012). The density of horse-keepership in Wales is highest in the South and particularly in the South East (Boden et al., 2012).

There are two major issues that in recent years have been identified in relation to horse welfare in Wales. These are fly grazing, which is the grazing of horses without the landowner's consent, and the conditions of both tethered and non-tethered animals who are grazed (often lawfully) on common 
lands in Wales. Charities provide a good source of information about horse welfare in Wales, as this is an issue which is largely left to charities and Local Authorities to respond to, even when initial complaints are directed to the police. There are few published studies relating to horse welfare in Wales, although there have been two notable exceptions comparing the welfare of horses who are tethered and those who are not tethered on common land in Wales (Samuel, Whay, \& Mullan, 2012; Mullan, Szmaragd, \& Hotchkiss, 2014): one of which was conducted in a residential district of Swansea in South Wales (Samuel et al., 2012).

The Royal Society for the Prevention of Cruelty to Animals (RSPCA) was established in 1824 and is now the UK's leading animal welfare charity. In 2013, the RSPCA published a report outlining the state of horse and pony welfare in Wales (RSPCA, 2013). This report highlighted that, in 2012, there had been 2,207 reports to the RSPCA regarding a total of 14,890 equines. In $97 \%$ of cases, the complaints from referring members of the public/and or other agencies were legitimate and reflected horses who were subsequently deemed, by trained inspectors, to be in need of assistance. In $92 \%$ of these cases, the incidents were categorized as "neglect," while in $2.7 \%$ of cases, they were associated with complete abandonment (see Table 1 ).

TABLE 1 Types of abuse associated with equines taken in by the RSPCA (Wales) in 2012

Incident subtype Number of cases Percentage of cases

\begin{tabular}{lrc}
\hline Abandonment & 397 & $2.7 \%$ \\
Beating & 66 & $0.4 \%$ \\
Damaged habitat & 1 & $<0.01 \%$ \\
Banned from keeping animals & 28 & $0.02 \%$ \\
Fighting & 2 & $0.01 \%$ \\
Flooding & 420 & $2.8 \%$ \\
Heat exposure & 18 & $0.1 \%$ \\
Improper killing & 107 & $0.7 \%$ \\
Mutilation & 6 & 0.04 \\
Neglect & 13,845 & $92 \%$ \\
Total & $14,890^{*}$ & \\
\hline
\end{tabular}

* In the text of the RSPCA report, 14,980 horses were reported to be involved in these incidents. However, the breakdown of cases yields a total of 14,89 , which is suggestive of a typographic error in the text of the original report (RSPCA, 2013, p. 15). 
The data relating to horses and ponies rescued by the swHP from January 1, 2014, to July 3, 2015, confirm this pattern. They are not related to the aforementioned complaints to the RSPCA. Of $5^{1}$ horses and ponies taken by the Society, into their premises and care, 35 had been abandoned by keepers. Where pregnant mares were taken in, the foals who were subsequently born at the sanctuary were counted as individuals. If the foals remained unborn at the cut-off point for data collection, the mare was counted but not her unborn foal. This applied in one case. An additional four abandoned equines were humanely destroyed by the Society in situ. This was because they were not in a strong enough condition to be transported to the sanctuary for rehabilitation. As a result, the total number of abandoned equines dealt with by the Society went up to 39 . In addition, 11 equines rescued by the SWHP, in that period, had suffered neglect while on a keeper's premises. In two cases, this was combined with acts of physical harm. One case involved an attempt at castration which left the pony mutilated and ultimately in need of surgery. The second case involved a facial injury resulting from improper use of a headcollar and tethering. In total, the Society dealt with 50 horses and ponies $(91 \%)$ who had suffered neglect/abandonment, out of an overall total of 55 horses attended to (only $5^{1}$ of whom were taken in by the society for rehabilitation/ rehoming). This proportion is strikingly similar to that reported by the RSPCA, which was $92 \%$ in 2012.

Taken together, the data available from both the RSPCA and the SWHP indicate that across Wales, the major threat to horses from humans arises from neglect (including total abandonment) rather than from deliberate acts of assault/violence.

\section{Materials and Methods}

The account that is offered here is based upon an analysis of data regarding the prevalence of equine abuse in Wales and the work undertaken in one significant charity (the SWHP) to rescue and rehabilitate equines. The research was subject to oversight by the ethics committee for the School of Social Sciences at Cardiff University.

Following the enactment of the Control of Horses (Wales) Bill, Local Authorities in Wales are empowered to seize horses who are located in any public place or on any other land in the Local Authority's area without lawful authority. Alongside the powers it offers to Local Authorities, the Act also specifies some responsibilities. One such responsibility relates to the maintenance of a "register of seized horses." Local Authorities are required to keep this and 
to make it available for public viewing. In order to collect information across Wales on the numbers of horses who had been seized by Local Authorities since the Bill came into force (January 1, 2014), a written request was made to all authorities asking for access to the information contained in their registers.

In 21, of 22, Local Authorities, permission was granted. One local authority was unable to respond in the time available but it did not refuse to take part, as such. Where registers existed, electronic access was generally provided. In one Local Authority, access was provided to the results of a series of data "enquiries" run by the Local Authority officer concerned. A register, as such, was not accessed in this instance.

In nine Local Authorities, horses were reported as having been seized and a register was maintained. In 12 Local Authorities, the responsible officers reported that no horses had been seized. In these authorities, officers either reported that they did not have a problem with fly grazing in their area (at least not one which was severe enough to warrant horse seizure) or they suggested that another authority, or the RSPCA, dealt with such problems. Registers were scrutinized and relevant case information was analyzed. Ultimately, these data were then compared with data in the public domain regarding multiple indicators of deprivation by Local Authority, numbers of caravans (used by travelling communities) by Local Authority, and areas of common land by Local Authority.

In addition to the data collected from Local Authorities, permission was granted by the SwHP allowing for the analysis of the individual records of all horses taken in by the charity between the January 1, 2014, and July 3, 2015 . These dates were selected to coincide with the introduction of powers associated with the enactment of the Control of Horses (Wales) Bill. The SWHP is a member of the National Equine Welfare Council (NEWC). NEWC collects data on new admissions to member charities, and these data show that in the period March 31, 2013, to March 31, 2014, the swHP had the fifth highest intake of new admissions in Wales.

This analysis of SwHP cases required visits to the charity and clarification from specific officers regarding individual, manually recorded, case histories. The data collection focused upon the characteristics of rescued horses and ponies (age, type, sex) as well as the circumstances of their rescue (area, source of referral), the type of harm they had suffered, and the medical treatment provided. This information was extracted from hand-written records, entered into Excel, and subsequently coded (e.g., by type of harm, type of treatment, etc.) and grouped (e.g., by age).

In addition to this material, the charity provided permission to approach their veterinary practice and request access to financial records. The practice 
kindly provided information regarding the cost of medical treatment for each of the horses/ponies who were rescued in the time period concerned. This information was cross-matched to the details regarding individuals made available by SWHP, so that analysis of costs (by age and sex for example) could be undertaken. Overall, the combined information provided an understanding of the financial costs associated with the rescue of horses and ponies of differing age and sex, the type of harm experienced by rescued ponies and horses, and the kinds of treatment and care required in such cases.

Finally, requests for data were made to both the RSPCA (Wales) and Natural Resources Wales. The request to the RSPCA was made in relation to the provision of recent figures pertaining to equine referrals and rescues. These were provided on a national basis for rescues and were also broken down by the Local Authority area of the referral. The request to Natural Resources Wales was related to up-to-date information on the distribution of land with associated common grazing rights across Wales.

Informal conversations with key informants in charities and Local Authorities assisted with the contextualization and interpretation of the data. Such conversations were not recorded or transcribed and did not constitute formal interviews.

Regarding the quantitative data collected, Local Authorities where horses had been seized were compared with those where horses had not been seized, in relation to numbers of traveller caravans and proportions of common land, using Mann-Whitney $U$ tests.

The correlations between complaints about equine abuse to the RSPCA and numbers of caravans were assessed using Spearman's rho. Similarly, the correlation between indicators of socio-economic deprivation, using the Welsh Index of Multiple Deprivation (WIMD), and horses seized was analyzed using Spearman's rho. Analyses were carried out using IBM SPSS Statistics, version 20.

The data collected from the SWHP and their veterinary practice were entered into Excel, and the analyses of these makes use of descriptive statistics.

\section{Results}

\section{Public Perceptions of the Causes of Equine Harm in Wales}

Fly Grazing and Travellers

The Control of Horses (Wales) Act 2014 was specifically devised to manage the problem of fly grazing, which had been identified by Local Authorities, the RSPCA, the media, and various interest groups, as a particular problem in Wales. A report drawn up in early 2013 by six leading horse welfare charities outlined the extent of the problem and termed it a "crisis" (RSPCA, Redwings, 
Blue Cross, World Horse Welfare, HorseWorld, The British Horse Society, 2013). The report stated:

It is estimated that almost 7,0oo horses are at risk in Britain, meaning that they are being irresponsibly fly grazed or their welfare is at risk because their owners cannot or will not give them the care they need. The largest number, an estimated 3,00o, are in Wales....

RSPCA ET AL., 2O13, p. 6

In the context of these figures, it is worth noting that the human population of Wales constitutes $4.8 \%$ of the UK population, suggesting that the problem of fly grazing in Wales is disproportionate (http://www.ons.gov.uk/ons/rel/ pop-estimate/population-estimates-for-uk--england-and-wales--scotland-and -northern-ireland/2013/index.html). Similarly, Wales includes less than $10 \%$ of the total UK land area $\left(21,224.63 \mathrm{~km}^{2}\right.$ of $248,531.52 \mathrm{~km}^{2}$ : http://www.ons.gov .uk/ons/guide-method/geography/beginner-s-guide/administrative/the -countries-of-the-uk/index.html).

The Control of Hoses (Wales) Act empowers (but does not instruct) Local Authorities to seize and impound any horse on a highway or in a public place when the authority has reasonable grounds to believe that that horse is there without authority. The Act further empowers authorities to seize and impound horses found on Local Authority land (without permission) and/or on private land, providing that the legal land occupier consents to their removal (http:// www.legislation.gov.uk/anaw/2014/3/pdfs/anaw_20140003_en.pdf).

For the purposes of this study, nine Local Authorities were able to supply copies of their registers of seized horses for the period from January 1, 2014, to May 6, 2015, with 12 reporting that they did not have such a register, as they had not seized any horses. Various explanations were volunteered by Local Authorities regarding lack of seizures. One explained that "we simply have not had the problem with fly grazing and abandonment encountered by our neighbouring authorities," and another wrote in a letter:

Although we do have a Seized Horse Register template document, to date we have not had any need to take any horses in to the council's possession and therefore we do not have any incidents to record nor a populated register to publish. Any incidents that we have dealt with regarding stray/ fly-grazed horses have fortunately been few in number and have been dealt with by working with the owners of the horses without the need to resort to seizure.

FLINTSHIRE, 2015 
These explanations highlight a number of issues. Firstly, we should be aware that recorded data are a product of social processes and do not perfectly reflect the underlying problems which they relate to. For example, sociologists have long since identified that recorded suicides cannot be taken to accurately represent all suicides (Douglas, 1967; Pescosolido \& Mendelsohn, 1986), that reports of accidents at work cannot be taken to reflect all accidents at work (Nichols, 1997; Ellis, Bloor, \& Sampson, 2010), and so forth. What is counted as "a suicide" and what is counted as "an accident" is a matter for local interpretation, and a number of social factors may be influential in such assessments. Statistics are best understood as social constructions, therefore, and here we are alerted to the fact that differences between Local Authorities which relate to the numbers of horses seized are not a perfect reflection of the local problems of fly grazing; however, in all cases, they are likely to reflect a combination of both the total number of horses fly grazed and local reporting and enforcement practices.

The explanations volunteered with regard to not having any returns of seized horses also alert us to some potential questions and explanations. If we consider the spatial distribution of population/settlement of common land and of major transport routes (see Figures 1 and 2), it is apparent that South Wales has higher concentrations of population, and of transport routes, than other areas of the country; this accords with the density of horses (as reported earlier). These factors will influence the reporting of horse abuse (which may be expected to be both more visible and, in the case of fly grazing, of greater public nuisance in more populated areas) as well as concentrations of horse keepership.

Further exploration of the data and informal discussions with key stakeholders (welfare officers in charities and in Local Authorities) suggest several factors that might also, usefully, be taken into account. Some stakeholders in animal welfare charities as well as some Local Authority officers have alluded in conversations to the idea that fly grazing can be explained by the local prevalence of travellers. This view is endorsed in the press:

Horses abandoned by travellers are often "fly-grazed," meaning they are left to graze illegally on public or private land. Charities cannot trace the owners because most travellers have ignored a law requiring all horses to carry a microchip and the national equine database, which linked each microchip to an owner, has been scrapped to save money.

ROWLEY, 2013 


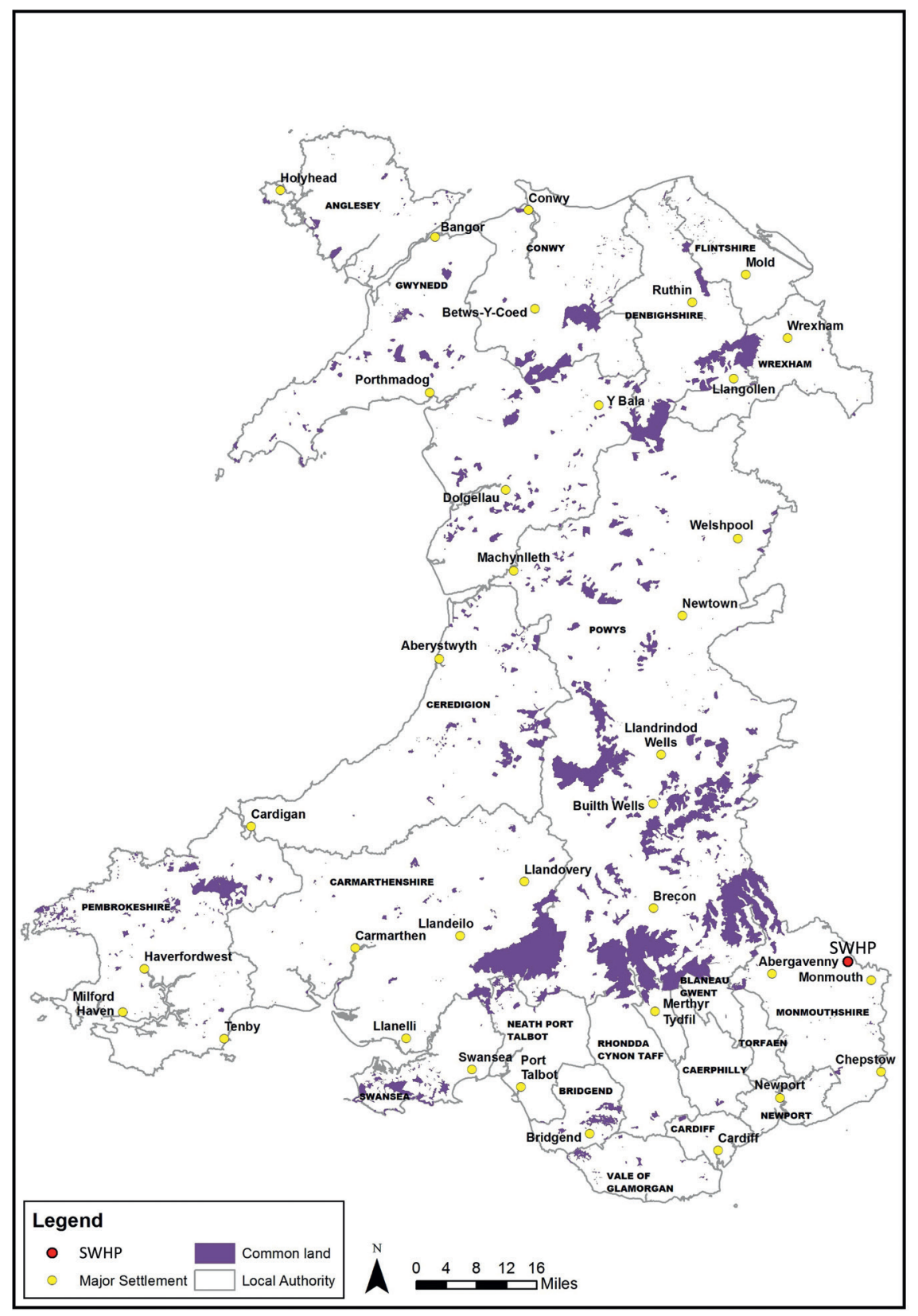

FIGURE 1 Map of Wales showing Local Authorities, common land, major settlements, and the location of $S W H P$. 


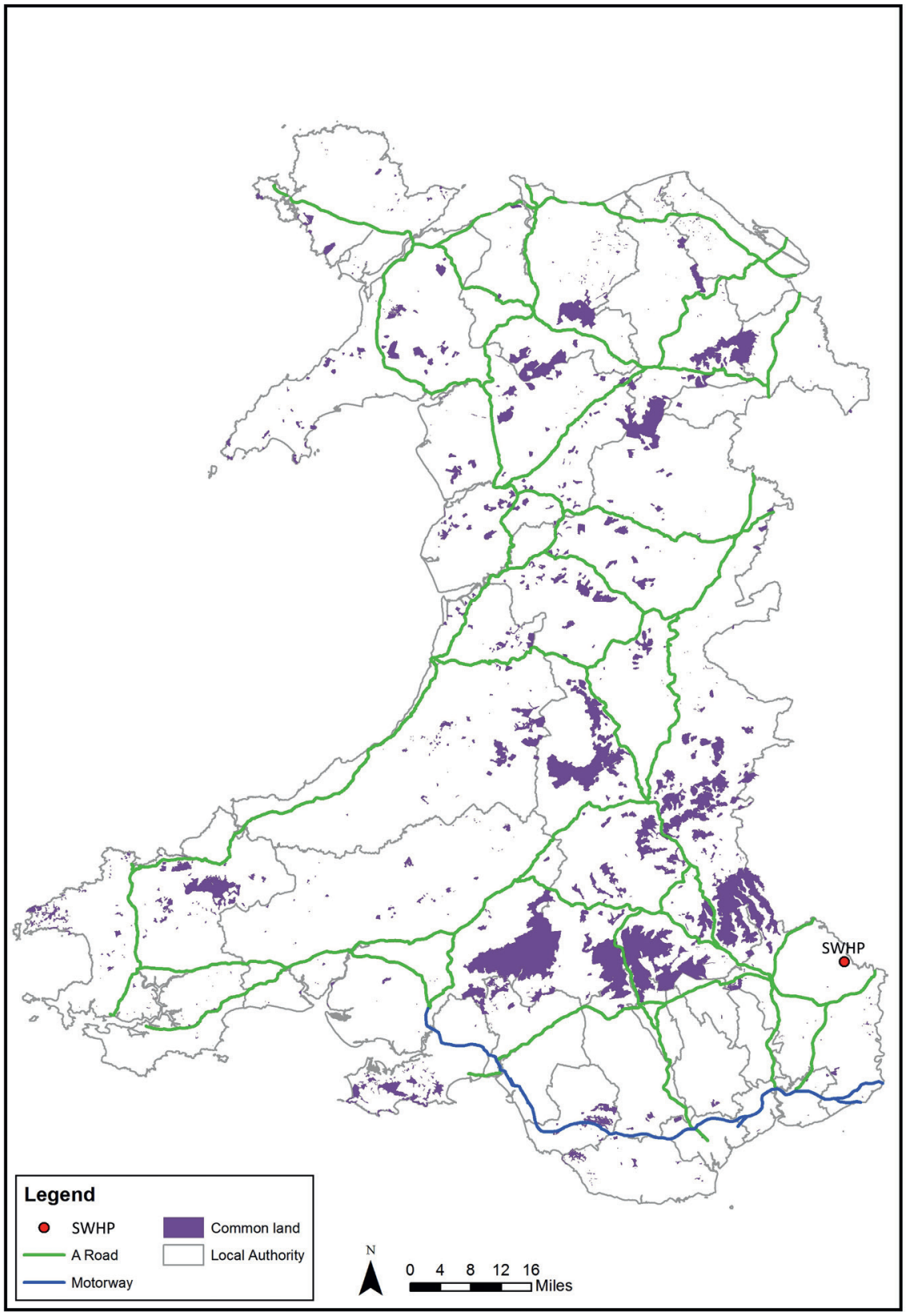

FIGURE 2 Map showing distribution of common land and major transport routes in Wales, with the location of $S W H P$. 
Temporary fly grazing is not an unusual practice among travellers who frequently graze their horses upon grass verges as they proceed on their journeys from place to place and have traditionally engaged in practices such as "sneaking horses into farmers' fields in the dead of night and then removing them before first light to avoid detection" (Levinson \& Silk, 2007). It could be argued that fly grazers are not in a position to select safe sites for their horses which are securely fenced, free from hazards (e.g., rusting metal), and supplied with safe drinking water. To this extent, it is possible to see that practices of fly grazing may be fraught with the potential for neglect, but this does not mean that we can assume that all fly grazing equates with neglect.

There is some evidence that travellers are knowledgeable about horses and have a high regard for their welfare. In their book about travellers in the UK, Levinson and Silk (2007) describe gypsies and travellers as having great affinity for horses. They also acknowledge, however, that cruelty is not unknown among these communities, and their account suggests that old-fashioned methods of "breaking-in" horses may still prevail. Horses have traditionally been widely traded by traveller communities in the UK, and commodification may also result in animal neglect and abuse. For example, in 2013, Tom Price, who is reported to have owned and traded 2,50o Gypsy cobs across Wales, was jailed for eight months having been found guilty of 57 animal welfare and cruelty charges (http://www.bbc.co.uk/news/uk-wales-23201997). Mr. Price traded horses to continental Europe for slaughter and human consumption, and within the UK and USA for other purposes. Despite such well-publicized accounts in the UK media, overall, the relationships between humans and horses in traveller communities are under-researched. The issues of tradition, the role of horses in traveller communities, questions of commodification, and gender, are all worthy of further study to establish a better understanding of the role and meaning of horses in traveller communities and the potential impact of these on equine welfare.

In relation to a continuum of equine care which ranges from the dedicated care of horses' complete needs to the neglect of some of their needs, and finally, the withdrawal of all care, we can see that abandonment is the most extreme form of human neglect in relation to horses - there is some evidence that this is linked to the availability of common land in some parts of Wales.

\section{Common Land and Abandonment/Neglect}

The SwHP data reveal that in the period January 1, 2014, to April 7, 2015, 31 of 39 abandoned horses and ponies dealt with by the Society had been found on common land. Most cases were from two locations: Cefn Gola mountain and Gelligaer common. However, horses and ponies had also been rescued from 
the Swansea marshes, and from Pencoed and Manmoel commons, demonstrating that abandonment on common land is a relatively extensive problem in South Wales. An online news article published in April 2015 outlined the extent of the problem on Gelligaer and proximate Merthyr commons as follows, "The commons are now home to around 500 ponies and colts with the majority of animals abandoned by their owners ... a number of the ponies are dying or suffering serious health problems from starvation" (Dewey, 2015).

Generally, commons ponies are descended from animals who has been deliberately bred and placed on the commons by identifiable keepers. Such keepers are usually locals with grazing rights to the commons. Some of the communities around the commons have established societies which are meant to oversee the management of such pony populations. Over time, however, many ponies have been abandoned and once abandoned, they have become feral and the passport/identification derogations which have been permitted by the Welsh government (and are connected with the establishment of the pony societies) have made subsequent identification of the legal keepers of these ponies problematic.

Indiscriminate breeding of the abandoned/feral populations has further complicated the matter. While there have been some reports from Local Authorities of clearing specific commons areas of ponies and horses whose keepers cannot be identified, there are many areas where such work has not been undertaken. To clear a common of 500 horses and ponies (as Gelligaer would apparently require) would represent a significant cost to Local Authorities at a time when their budgets have been subject to repeated annual reductions. In the absence of high levels of complaints from the public, it is not likely that many abandoned ponies and horses on commons in Wales would come to the attention of the Local Authorities or appear on the seized horses register.

\section{Poverty and the Market for Horses}

The poor economic climate (the UK economy has been characterized by a marked lack of growth since 2008) combined with the over-supply of horses across the UK, is widely held to play a part in explaining equine abandonment. Horses and ponies are costly to keep. They require food, shelter, water, and attention from qualified dentitions, farriers, and vets. It is reasonable then to consider whether there is a relationship between socio-economic deprivation and equine abandonment.

In relation to the commons, a frequently offered explanation of equine abandonment relates to the low "sale value" of horses and ponies in the UK at the current time. As the chairman of the Gelligaer and Merthyr Commons 
Association put it, "there is no money in horses." He suggested that, "There is no money in horses at the moment and a lot of people don't want them ... we work with a charity to try and rehome them but unfortunately some will be destroyed" (Dewey, 2015).

\section{Exploring Established Explanations of Horse Neglect in Wales}

The small numbers of Local Authorities in Wales which have seized horses (see Table 2) poses a challenge to efforts to establish statistical correlations relating horse seizures to the prevalence of common land, traveller populations, or poverty. Indeed, interrogation of the data along these lines reveals little of conventional "statistical significance." However, what do emerge are some patterns in the data which indicate which lines of inquiry are worthy of future research.

TABLE 2 Summary of indicators used in the research by local authority

\begin{tabular}{llllll}
\hline Local Authority & No. of horses & RSPCA & No. of & Common land \% LsoAs in \\
seized by & referrals & caravans in & in each local & each local \\
local & in Wales & each local & authority & authority \\
authorities & by local & authority & among most \\
& authority & & deprived 20\% \\
& & & & in Wales*
\end{tabular}

\begin{tabular}{|c|c|c|c|c|c|}
\hline Date/measure & $1 / 1 / 14-1 / 6 / 15$ & $(2014)$ & $(2015)$ & (hectares) & $(2014)$ \\
\hline Swansea & 302 & 1,426 & 31 & $8,374 \cdot 35$ & $24 \cdot 3$ \\
\hline Cardiff & 104 & 461 & 177 & $109 \cdot 91$ & 27.1 \\
\hline Caerphilly & 51 & 431 & $\mathrm{O}$ & $3,598.48$ & 28.2 \\
\hline Bridgend & 34 & 164 & 6 & $3,046.48$ & 22.7 \\
\hline Camarthenshire & 30 & 2,563 & 93 & $1,5630.7$ & 10.7 \\
\hline $\begin{array}{l}\text { Vale of } \\
\text { Glamorgan }\end{array}$ & 11 & 391 & 23 & 516.27 & 15.2 \\
\hline Merthyr Tydfil & 10 & $5^{\circ}$ & $5^{\circ}$ & $2,928.56$ & 30.6 \\
\hline Wrexham & 4 & 295 & 45 & $2,087.49$ & 12.9 \\
\hline Powys & 3 & 485 & 39 & $6,8937 \cdot 1$ & \\
\hline Blaenau Gwent & $\mathrm{O}$ & 221 & 20 & $3,687.27$ & 46.8 \\
\hline $\begin{array}{l}\text { Rhondda Cynon } \\
\text { Taff }\end{array}$ & $\mathrm{O}$ & 194 & 30 & $1,981.15$ & 31.2 \\
\hline Newport & $\mathrm{O}$ & 338 & 67 & $969 \cdot 36$ & 30.5 \\
\hline Neath Port Talbot & $\mathrm{O}$ & 449 & 89 & $2,085.06$ & $29 \cdot 7$ \\
\hline
\end{tabular}


TABLE 2 Summary of indicators used in the research by local authority (cont.)

\begin{tabular}{llllll}
\hline Local Authority & No. of horses & RSPCA & No. of & Common land & \% LSOAs in \\
& seized by & referrals & caravans in & in each local & each local \\
local & in Wales & each local & authority & authority \\
authorities & by local & authority & & among most \\
& & authority & & & $\begin{array}{l}\text { deprived 20\% } \\
\text { in Wales** }\end{array}$
\end{tabular}

\begin{tabular}{lrrrcl}
\hline Torfaen & 0 & 135 & 70 & $2,953.91$ & 25 \\
\hline Denbighshire & 0 & 124 & 0 & $7,158.5$ & 17.2 \\
\hline Isle of Anglesey & 0 & 663 & 14 & 803.19 & 15.9 \\
\hline Conwy & 0 & 96 & 3 & 1,1692 & 12.7 \\
\hline Flintshire & 0 & 469 & 88 & 790.57 & 12 \\
\hline Gwynedd & 0 & 256 & 13 & $1,9975.1$ & 4.1 \\
\hline Ceredigion & 0 & 398 & 4 & $1,0448.5$ & 2.2 \\
\hline Monmouthshire & 0 & 154 & 1 & $4,925.16$ & 0 \\
\hline Pembrokeshire* & & 1,017 & 157 & $5,302.15$ & 8.5 \\
\hline Totals & 549 & 10,780 & 1,020 & $178,001.26$ & \\
\hline
\end{tabular}

* Pembrokeshire was unable to respond within the necessary time frame.

** These data are based upon the Welsh Index of Multiple Deprivation (2014). The figures relate to Lower Level Super Output Areas (LSOAs) which can be described as sub-areas of each local authority. The figure shown describes the percentage of LSOAs in each Local Authority which appear in the most deprived $20 \%$ of LSOAs in Wales. As such, $24.3 \%$ of the LSOAs (subareas) in Swansea are among the $20 \%$ most deprived LSOAs across Wales.

\section{Seized Horses and Traveller Populations}

If we compare the numbers of traveller caravans reported in their area by the authorities who have seized horses, with the number of caravans reported by authorities who have not seized any horses, we see that there is an interesting, although not significant, difference (Mann-Whitney $U=40.05, p=$ 0.35): more caravans are reported in Local Authorities with seized horses (see Figure 3).

This pattern supports the supposition that traveller movements may be associated with horse seizures, but the relationship is not sufficiently strong to conclude that this is definitely the case.

\section{Seized Horses and Common Lands}

A similar picture is presented when we look at the proportion of common land within the boundaries of authorities where horses have been seized and 


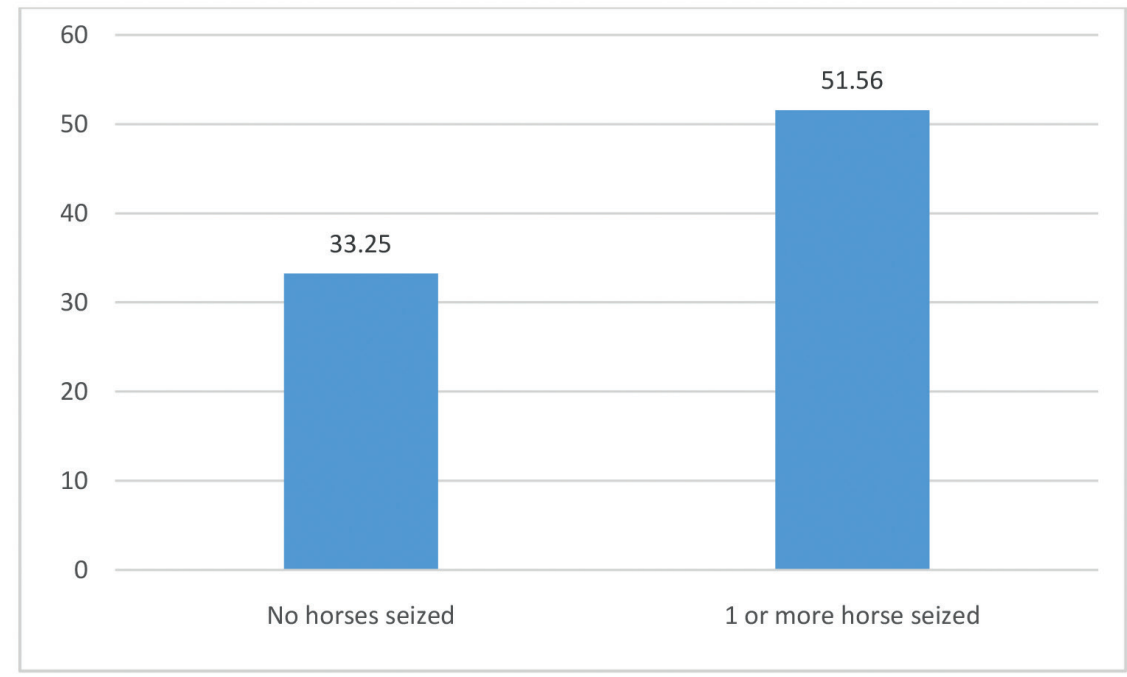

FIGURE 3 Mean number of traveller caravans in authorities with seized horses and in those without seized horses.

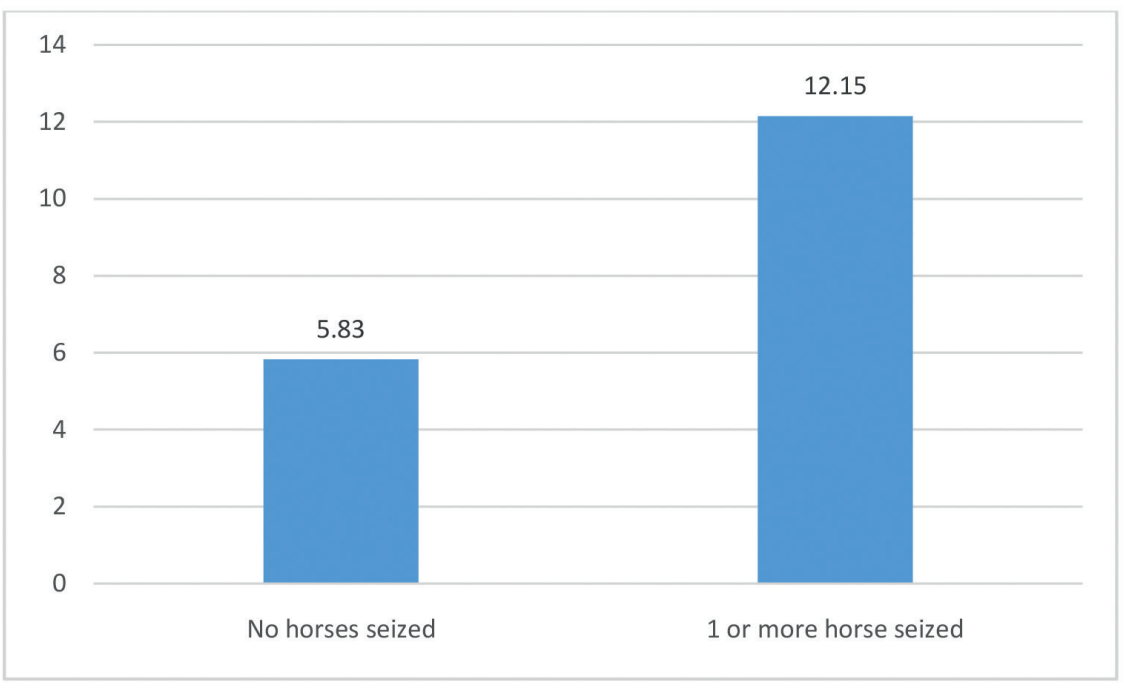

FIGURE 4 Median proportion(\%) of common land in authorities with seized horses and in those without seized horses.

the proportion where they have not. The results indicate that the proportions of common land are higher in Local Authority areas where horses have been seized (see Figure 4 ) but that once again this result is not of statistical significance $(U=47.00, p=0.65)$. 
The patterns in these data are of greater interest than the lack of statistical significance, for a number of reasons. For example, the area of common ground should not necessarily be expected to correlate with the numbers of seized horses if cultural and socio-historic factors have impacted traditional land use, and given that the density of horse keepership varies across Wales. It would be better to consider the hectares where commons ponies traditionally graze than the total number of hectares of commons per se when looking for correlations with horse seizure, but regrettably, this information is not available.

In relation to travellers, it is interesting to note that there is a statistically significant correlation between the number of traveller caravans in Local Authorities in Wales and the number of horse welfare complaints to the RSPCA (Spearman's $r h o=0.47, p=0.03$; see Figure 5 ). At first reading, this might indicate higher levels of concern among the public regarding horse welfare in areas with high numbers of travellers, and this concern could be a result of prejudice which is relatively commonplace (Levinson \& Sparkes, 2003). However, the high number of complaints which the RSPCA typically find to be well-founded makes such an explanation less likely (RSPCA, 2013), suggesting that this is perhaps an area where more careful exploration is required.

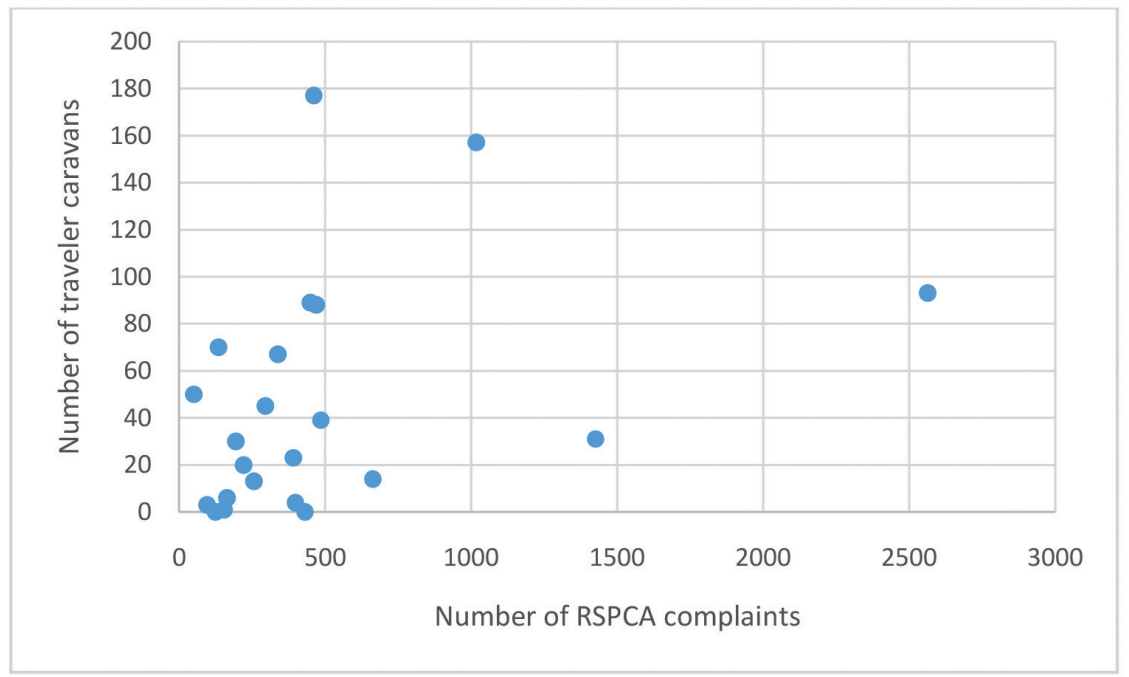

FIGURE 5 Scatterplot showing correlation between the number of caravans in Local Authorities in Wales and the number of horse welfare complaints to the RSPCA. 


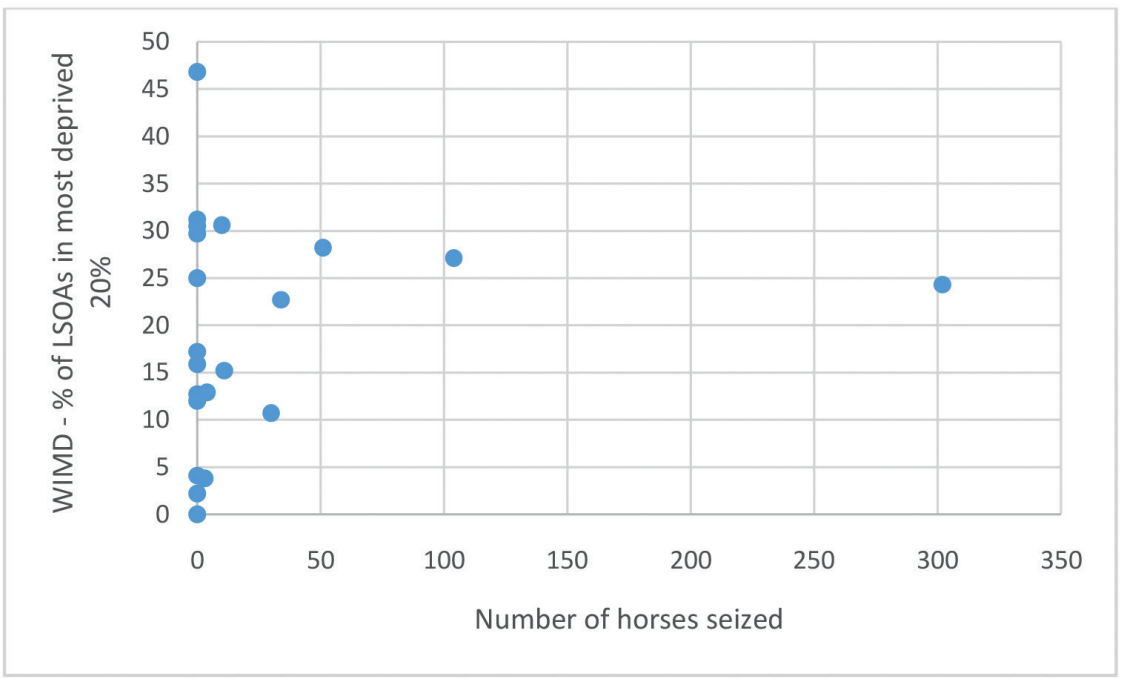

FIGURE 6 Scatterplot showing the correlation between number of horses seized in Local Authorities in Wales and Welsh Index of Multiple Deprivation (WIMD; \% of Lower Level Super Output Areas [LSOAs] in the most deprived $20 \%$ ).

\section{Socio-Economic Deprivation and Horse Seizures}

Finally, it is worth noting that when a measure of deprivation was considered in relation to patterns of horse seizure across Wales (Figure 6), there was very little correlation (Spearman's $r h o=0.10, p=0.67$ ).

This indicates that social deprivation is not likely to be associated with horse and pony neglect in Wales. It does not rule out the possibility that falling values of horses combined with rising costs for their "keep" have contributed to abandonment by more affluent members of society who may reasonably be expected to be disproportionately represented among horse keepers.

\section{Mitigating Harm: Work of SWHP}

Of the 55 horses the SWHP dealt with from January 1, 2014, to April 7, 2015, 39 were abandoned by their keepers. In rescuing these horses and ponies, the SWHP incurs costs from the unpaid time of volunteers, the paid time of staff, transport, medication, feed, farrier and dental services, and veterinary treatment. This list is not exhaustive, and in addition, staff and volunteers at the charity also bear emotional costs as they witness and deal with distressing situations where abandoned horses have been involved in road traffic accidents or where malnourished mares with foals at foot have collapsed as a result of the attentions of feral stallions. 


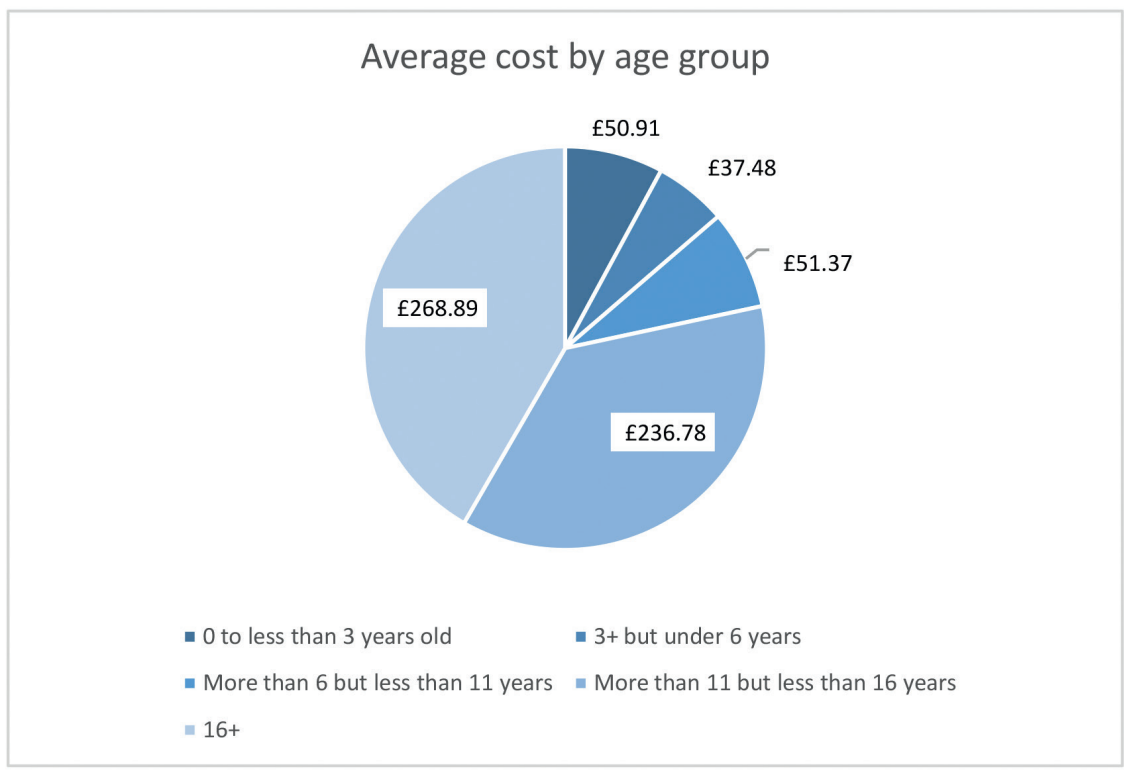

FIGURE 7 Average cost to SWHP for veterinary treatment by age.

If consideration is limited to the veterinary costs associated with the treatment of new arrivals, then the $5^{1}$ animals who were taken into the care of the SWHP in the 18-month period between January 1, 2014, and March 7, 2015, incurred an average bill of $£ 88.18$ each. Of the rescued animals, 28 were male and 23 were female. These figures include three fillies who were born at the SWHP but do not include unborn animals. The average cost of treating males $\left(£_{71.33)}\right)$ was lower than the average cost for females (£108.71). There were also considerable differences in costs related to age, with older animals (over 11) being more than five times more costly than younger ones (see Figure 7).

Some horses whose feet and teeth had been badly affected by neglect also incurred significant costs for dentistry and farriery. For example, one 18-yearold mare was rescued with excessively long hooves causing pain. In addition to pain relief, she required treatment from the farrier every five weeks at a cost of $£_{5} \circ$ per visit. More commonly, regular farriery costs £2o per animal and is conducted less frequently.

Thus, while horses and ponies in Wales suffer harm from humans, in a variety of forms, it is important to appreciate that they are also subject to a great deal of care and concern from many individuals and groups. The running costs for the SWHP in 2014 amounted to $£ 251,359$, and this was raised through a range of fundraising events and activities such as sponsored "duck races" (numbered 
plastic ducks are released on a river and the first to cross a line are designated "winners") table-top sales, dog shows and open days, as well as via legacies and general donations of food and materials from companies. In 2015, the sWHP embarked upon a program of contraceptive vaccination for abandoned equines on Gelligaer common where indiscriminate breeding and overpopulation is resulting in considerable harm. The contraceptive lasts for one season and the cost of treatment per animal is £25. By the summer of 2015, a total of 250 vaccinations had been administered via darting. In 2016, an expansion of the program was announced with a dedicated stream of funding and, in a new development, the support of some commoners. In its Winter 2015 newsletter, the Society noted:

Great progress has been made by Philip our General Manager to give a contraceptive vaccine to a large number of ponies on Gelligaer and the surrounding area. He has worked with Local Authorities who have been very supportive of this initiative and at long last we are getting the commoners to work with us.

SWHP, 2015

\section{Discussion}

\section{Exploring Human-Horse Relationships}

In recent decades, there have been efforts by social scientists in a variety of disciplines to discuss the significance of animal abuse as a predictor of future violence against humans (Mead, 1964; Hutton, 1998; Kellert \& Felthous, 1998; Bell, 2001). There have also been efforts to describe some of the ways that threats against animals are used by abusers of humans to retain control over their victims (Ascione, 1998; Flynn, 200o). However, there has been much less work undertaken on the relationships between humans and non-human animals in society more generally. This is despite work undertaken as early as the 19th century highlighting the complex and contradictory ways in which such relationships are manifested, and their connections with mainstream sociological concerns such as culture and social class (Jevons, 1876).

In sociology, this curious "blindness" to the interaction between humans and other animals in contemporary society is slowly changing with the emergence of human-animal studies (Wilkie, 2015, p. 326). These address the need for sociologists to attend to what Bryant (1979) has referred to as the "zoological connection," and the multifaceted and complicated web of relations between humans and other animals (Shapiro, 2008). To some extent, this relatively 
recent "animal turn" (Wilkie, 2015, p. 326) has focused, in empirical terms, on studies of human and non-human animal interaction. Research has been undertaken in laboratories where animals are used in scientific experiments; in animal shelters where rescued animals are both cared for and (in some settings) euthanized by workers; and among professionals, such as trainers/vets, working with animals and with their keepers (Arluke \& Sanders, 1996; Alger \& Alger, 1999).

The development of research in this area has been relatively slow, notwithstanding the publication of some notable texts which provide a framework within which such work might become established (e.g., Franklin, 1999). It is also the case that in many quarters, the "animal turn" in sociology can be said to have met with resistance. In this context, Flynn's (2003) account of his (ultimately successful) attempt to establish an undergraduate course focused upon Animals and Society at the University of South Carolina, is instructive (Flynn, 2003).

Within this "animal turn," there have been efforts by some writers to move towards a specifically sociological understanding of animal abuse (Beirne, 1997; Flynn, 2001). Hitherto such concerns have tended to be associated with the discipline of psychology and have made use of "psychopathological explanatory" models which assume that mental health problems/disorders lie behind individual acts of cruelty and abuse (Flynn, 2001, p. 74). In locating an understanding of abusive acts more broadly, in the context of the social world, sociologists can reasonably hope to extend the appreciation of the factors that underlie such acts to include a grasp of the role of power relations, gender norms, cultural values, socio-economic inequalities, and socialization (NB this list is intended to be illustrative rather than exhaustive). Such factors have been shown to constrain and shape human/non-human relationships more comprehensively. For example, meat consumption and associated human/ non-human relationships have been shown to have a strong gender dimension (Rothgerber, 2013). Similarly, some accounts have highlighted the importance of social class in shaping human/non-human relations: in the world of professional horse sports in the UK, Dashper (2014) demonstrates how social class impacts the relationships between equines and their riders; and in her study of the professional "A" Circuit in Canada, Coulter (2014) examines the commodification of horses and the class structure underlying the mechanics of competition.

In a similar vein, this paper concerning both the care and neglect of horses in Wales seeks to move towards a broader, more sociological, understanding of both horse abuse and "horse care." A first step towards the achievement of such an understanding is to consider the particular patterns of horse-human relationships. The patterns alert us to the ways in which different attitudes to 
horses and their welfare may be distributed across populations; this knowledge is a necessary precursor to having a deeper appreciation of the motivations of social groups in relation to human-horse interaction.

In undertaking a preliminary analysis of statistical data about widely promulgated explanations of horse neglect, it has been difficult to arrive at definitive conclusions. However, the patterns within the data are highly suggestive of relationships between neglect and fly grazing, neglect and common land, and neglect and traveller populations within Wales. However, the data presented here do not imply that there is a relationships between socio-economic indicators of deprivation and horse neglect. This is a finding which contrasts strongly with research into animal torture and acts of deliberate harm where psychologists have repeatedly found associations with measures of inequality (e.g., Vaughn et al., 2009).

\section{Conclusion}

Risks posed by humans to equines in Wales center on neglect. Historically, in the UK, this has not been the case, and more violent forms of abuse such as horse beatings were commonplace in the 18th and 19th centuries (Franklin, 1999; Perkins, 2003). Today, deliberate acts of cruelty against horses have not disappeared, but they have been eclipsed by neglect and abandonment. Typically, a "common sense" understanding of such acts focuses on individuals and their personal characteristics. However, an analysis of the data in Wales suggests that there are patterns to such abuse which require a deeper understanding of issues related to land use and to culture. As such, it would be valuable to undertake detailed qualitative studies to understand: the role of equines in different communities; access to land; relationships with authorities; the commodification of horses; attitudes to equine care; and the role of horse keepership (e.g., in relation to wealth, status, gender, etc.).

The understanding that such studies would facilitate would allow for better targeting of strategy by both governmental and non-governmental bodies, and would provide a better chance of achieving the longer-term objectives of those seeking to address issues of equine abuse.

\section{Acknowledgments}

I would like to thank the SWHP, Local Authorities in Wales, the RSPCA, SEAB (Welsh Government), and Abbey Equine Clinic for their assistance with access 
to data. I would also like to thank Amaha Senu, Samuel Jones, and Emma Wadsworth, in particular, for advice and contributions. I would like to dedicate this article to the memory of Jenny MacGregor MBE who founded the SwHP and sadly died in November 2017.

\section{References}

Alger, J., \& Alger, S. (1999). Cat culture, human culture: an ethnographic study of a cat shelter. Society \& Animals, 7(3), 199-218.

Arluke, A., \& Sanders, C. (1996). Regarding animals. Philadelphia, PA: Temple University Press.

Ascione, F. (1998). Battered women's reports of their partners' and their children's cruelty to animals. Journal of Emotional Abuse, 1(1), 199-133.

Beirne, P. (1997). Rethinking bestiality: towards a concept of interspecies sexual assault. Theoretical Criminology, 1, 317-340.

Bell, L. (2001). Abusing children - abusing animals. Journal of Social Work, 1(2), 223-234.

Boden, L., Parkin, T., Yates, J., Mellor, D., \& Kao, R. (2012). Summary of current knowledge of the size and spatial distribution of the horse population within Great Britain. BMC Veterinary Research, 8(43). DoI: 10.1186/1746-6148-8-43.

Bryant, C. (1979). The zoological connection. Animal-related human behaviour. Social Forces, 58(2), 399-421.

Control of Hoses (Wales) Act 2014. National Assembly for Wales. http://www .legislation.gov.uk/anaw/2014/3/pdfs/anaw_201400o3_en.pdf.

Coulter, K. (2014). Herds and hierarchies: class, nature, and the social construction of horses in equestrian culture. Society \& Animals, 22, 135-152.

Dashper, K. (2014). Tools of the trade or part of the family? Horses in competitive equestrian sport. Society \& Animals, 22, 352-371.

Dewey, P. (2015). Number of abandoned ponies in Gelligaer and Merthyr Tydfil "reaching crisis point"-claim. WalesOnline, April 12. http://www.walesonline.co.uk/ news/wales-news/number-abandoned-ponies-gelligaer-merthyr-9o28101.

Douglas, J. (1967). The social meanings of suicide. Princeton, NJ: Princeton University Press.

Duncan, R. (1964). Ronald Duncan Literary Foundation: the horse. http://www.ronald duncanfoundation.co.uk/the-horse.

Ellis, N., Bloor, M., \& Sampson, H. (2010). Patterns of seafarer injuries. Maritime Policy and Management, 38(1), 81-92.

Flintshire. (2015). Unpublished personal correspondence.

Flynn, C. (2000). Woman's best friend: pet abuse and the role of companion animals in the lives of battered women. Violence Against Women, 6(2), 162-177. 
Flynn, C. (2001). Acknowledging the "zoological connection," a sociological analysis of animal cruelty. Society \& Animals, 9(1), 71-87.

Flynn, C. (2003). A course is a course, of course, of course (unless it's an Animals and Society Course): Challenging boundaries in academia. The International Journal of Sociology and Social Policy, 23(3), 94-108.

Franklin, A. (1999). Animals and modern culture: a sociology of human-animal relations in modernity. London, United Kingdom: Sage.

Government of Wales Act 1998. Chapter 38. London: The Stationery Office Ltd. http:// www.legislation.gov.uk/ukpga/1998/38/pdfs/ukpga_19980o38_en.pdf.

Hutton, J. (1998). Animal abuse as a diagnostic approach in social work: a pilot study. In R. Lockwood \& F. Ascione (Eds.), Cruelty to animals and interpersonal violence: readings in research and application (pp. 415-420). West Lafayette, IN: Purdue University Press.

Jevons, W. (1876). Cruelty to animals — a study in sociology. Fortnightly Review, May 1865-June 1934; May 19. 113 Applied Social Sciences Indexes and Abstracts (ASSIA), p. 671 .

Kellert, S., \& Felthous, A. (1998). Childhood cruelty towards animals among criminals and non-criminals. In R. Lockwood \& F. Ascione (Eds.), Cruelty to animals and interpersonal violence: readings in research and application (pp. 194-210). West Lafayette, IN: Purdue University Press.

Levinson, M., \& Silk, A. (2007). Dreams of the road: Gypsy life in the West Country. Edinburgh, United Kingdom: Birlinn.

Levinson, M., \& Sparkes, A. (2003). Gypsy masculinities and the school-home interface: exploring contradictions and tensions. British Journal of Sociology of Education, 24(5), 587-6o3.

Mead, M. (1964). Cultural factors in the cause of pathological homicide. Bulletin of Menninger Clinic, 28, 11-22.

Mullan, S., Szmaragd, C., Hotchkiss, J., \& Whay, H. (2014). The welfare of long-line tethered and free ranging horses kept on public grazing land in South Wales. Animal Welfare 23, 25-37. DOI: 10.7120/og627286.23.1.025.

Nichols, T. (1997). The sociology of industrial injury. London, United Kingdom: Mansell. Perkins, D. (2003). Romanticism and animal rights 1790-1830. Cambridge, United Kingdom: Cambridge University Press.

Pescosolido, B., \& Mendelsohn, R. (1986). Social causation or social construction of suicide? An investigation into the social organisation of official rates. American Sociological Review 51(1), 80-100.

Rothgerber, H. (2013). Real men don't eat (vegetable) quiche: masculinity and the justification of meat consumption. Psychology of Men \& Masculinity, 14(4), 363-375.

Rowley, T. (2013). They abandon horses, don't they? The Telegraph, Jan 8. http://www .telegraph.co.uk/lifestyle/pets/10216687/They-abandon-horses-dont-they.html. 
RSPCA. (2013). Equine welfare indicators. RSPCA. http://politicalanimal.org.uk/wp -content/uploads/2014/og/RSPCA-Cymru-Equine-Indicators-2013.pdf

RSPCA, Redwings, Blue Cross, World Horse Welfare, HorseWorld, \& The British Horse Society. (2013). Left on the verge: in the grip of a horse crisis in England and Wales. http://politicalanimal.org.uk/Horse-crisis-report-June-2013.pdf.

Samuel, E., Whay, H., \& Mullan, S. (2012). A preliminary study investigating the physical welfare and welfare code compliance for tethered and free-ranging horses on common land in South Wales. Animal Welfare, 21, 593-598.

Shapiro, K. (2008). Human-animal studies: growing the field, applying the field. Ann Arbor, MI: Animals and Society Institute.

SWH P. (2015). Newsletter of the society for the welfare of horses and ponies. Winter.

Vaughn, M., Fu, Q., DeLisi, M., Beaver, K., Perron, B., Terrell, K., \& Howard, M. (20o9). Correlates of cruelty to animals in the United States: results from the National Epidemiologic Survey on Alcohol and Related Conditions. Journal of Psychiatric Research, 43, 1213-1218.

Welsh Government. (2012). Equine identification \& the semi-feral ponies of Wales. http://gov.wales/topics/environmentcountryside/ahw/horses/equineidsemiferalp onies/?lang=en

Welsh Government. (2013). Fly grazing and the abandonment of horses and ponies: action plan. http://gov.wales/docs/drah/publications/131014-control-horses-bill-action -plan-en.pdf.

Welsh Government. (2014). Welsh index of multiple deprivation 2014. Knowledge and analytical services. www.cymru.gov.uk.

Wilkie, R. (2015). Multispecies scholarship and encounters: changing assumptions at the human-animal nexus. Sociology, 49(2), 323-339. 